\title{
High dose prednisolone treatment of leprosy patients undergoing reactions is associated with a rapid decrease in urinary nitric oxide metabolites and clinical improvement
}

\author{
THOMAS SCHÖN* ${ }^{*}$ RUTH LEEKASSA*, \\ NEGUSSIE GEBRE ${ }^{+}$, TOMMY SUNDQVIST*, \\ ELISABETH BIZUNEH $^{* *} \&$ SVEN BRITTON ${ }^{+}$ \\ ${ }^{*}$ Department of Medical Microbiology, Faculty of Health Sciences, \\ Linköping University, Sweden \\ ${ }^{* *}$ ALERT, All Africa Leprosy Relief and Training Hospital, Addis \\ Ababa, Ethiopia \\ ${ }^{+}$AHRI, Armauer Hansen Research Institute, Addis Ababa, Ethiopia
}

Accepted for publication 16 June 2000

Summary Evidence is accumulating that nitric oxide (NO) produced by macrophages has a role in the pathogenesis of reactions in leprosy. We followed the urinary levels of the metabolites of $\mathrm{NO}$ [nitrite $\left(\mathrm{NO}_{2}{ }^{-}\right)$and nitrate $\left(\mathrm{NO}_{3}{ }^{-}\right)$] and the clinical response to prednisolone treatment in leprosy patients $(n=9)$ admitted to ALERT leprosy hospital Addis Ababa, Ethiopia, because of reversal reaction (RR) or erythema nodosum leprosum (ENL). In untreated reactional leprosy patients, the levels of urinary NO metabolites $(1645 \pm 454 \mu \mathrm{M}, n=9, \mathrm{ENL}=4, \mathrm{RR}=5)$ decreased significantly 2 weeks after high dose prednisolone treatment $(1075 \pm 414 \mu \mathrm{M}, P<0.05)$, and remained stable $4(895 \pm 385 \mu \mathrm{M}, P<0.02)$ and 6 weeks following treatment initiation $(1048 \pm 452 \mu \mathrm{M}, P<0.02)$. This decrease was also present when the reactional patients were subdivided according to the type of reaction (ENL, RR) and coincided with a clinical improvement. In patients showing a poor clinical response to steroids, no or minor effects on the urinary NO metabolite levels were observed. We conclude that there is a correlation between the decrease in urinary NO metabolites and a favourable clinical response after high dose prednisolone treatment of reactional leprosy patients.

\section{Introduction}

Leprosy caused by Mycobacterium leprae is a polar disease with a spectrum ranging from lepromatous leprosy (LL) with a marked Th2 type response and large numbers of bacilli, to the tuberculoid type (TT) showing a Th1 response with small numbers of bacilli. ${ }^{1,2}$ It is a

Correspondence to: T. Schön, Department of Medical Microbiology, Faculty of Health Sciences, 58185 Linköping, Sweden (e-mail: t.schon@telia.com) 
chronic inflammatory disease primarily affecting the skin and peripheral nerves and the clinical manifestations depend on the host immune response. Reversal reactions (RR) that occur in the unstable borderline cases [borderline lepromatous (BL) and borderline tuberculoid (BT)], are associated with acute inflammation in skin lesions and an increase in cellmediated immunity, where nerve damage from acute neuritis may be rapid and severe.,4 Erythema nodosum leprosum (ENL) occurs in LL and BL cases and is thought to be a immune complex mediated reaction, ${ }^{5}$ but cell mediated immunity has also been implicated in this type of reaction. ${ }^{6}$ Both ENL and RR patients are treated with high dose corticosteroids to prevent irreversible nerve damage and subsequent loss of function. ${ }^{7}$

In response to Th1 cytokines, high levels of nitric oxide (NO) are produced from Larginine by activated inflammatory cells such as macrophages expressing the inducible nitric oxide synthase (iNOS) ${ }^{8-10} \mathrm{NO}$ is highly unstable and decays to its stable end products nitrate and nitrite, which are eliminated in the urine. ${ }^{8} \mathrm{We}$ have previously shown increased urinary levels of the $\mathrm{NO}$ metabolites $\mathrm{NO}_{2}{ }^{-} / \mathrm{NO}_{3}{ }^{-}$in leprosy patients in $\mathrm{RR} .{ }^{11} \mathrm{~A}$ recent report has described the presence of iNOS in tissue macrophages from patients undergoing reversal reaction. ${ }^{12}$ Thus, NO seems to play a role in the pathogenesis of reactional leprosy. The aim of this study was to investigate the effects of prednisolone treatment on the urinary levels of NO metabolites in correlation to the clinical response in patients suffering from the two different types of reactions in leprosy.

\section{Materials and methods}

\section{PATIENTS}

Patients included in the study were subjects admitted to the wards of ALERT hospital, Addis Ababa, Ethiopia in August to October 1998 who had a typical clinical picture of ENL or RR and did not show signs of co-existing diseases $(n=9$, Table 1). One patient was excluded because of displacement of the treatment record. The reactional patients were diagnosed and classified as described by Jopling and Ridley ${ }^{1,3}$ by experienced leprosy physicians. The clinical criteria used for the definition of the reactions were: $R R$, erythematous swelling of the existing leprosy lesions, appearance of new lesions that were not relapsing leprosy or ENL and onset or worsening of neuritis (new sensory or motor symptoms, peripheral nerve tenderness); $E N L$, painful and/or tender erythematous subcutaneous nodules in the skin not related to former leprosy lesion, fever and malaise and any of the following symptoms: tender peripheral nerves (neuritis), painful testicular swelling (orchitis), joint pain (arthritis), or painful swollen fingers (dactylitis). The clinical diagnosis were confirmed through histopathological diagnosis according to the classification by Jopling. ${ }^{1}$

The patients were initially treated orally with 40-60 mg prednisolone per day for 2 weeks and the dose was reduced by 5-10 mg every second week according to the clinical response. Multidrug therapy (MDT) was continued in previously treated patients and initiated in previously untreated patients. Peripheral nerve function were assessed during prednisolone treatment by voluntary muscle testing (VMT) and sensation testing (ST) of the hands and feet of the patients.

The clinical response to prednisolone treatment during the study period was evaluated by the leprosy physician and classified as follows: poor response, no improvement of erythematous skin lesions (such as diminishing erythema, nodules), persisting pain or tenderness of skin lesions and/or peripheral nerves and loss of peripheral nerve function assessed by VMT/ 
Table 1. Reactional leprosy patients included in the study. $\mathrm{BL}=$ borderline lepromatous, $\mathrm{BT}=$ borderline lepromatous, $\mathrm{LL}=$ lepromatoid lepromatous, $\mathrm{RR}=$ reversal reaction, $\mathrm{ENL}=$ erythema nodosum leprosum, $\mathrm{SR}=$ sedimentation rate, $\mathrm{BI}=$ bacillary index, $\mathrm{MDT}=$ multidrug treatment, $\mathrm{ND}=$ no data

\begin{tabular}{lllcccccc}
\hline Patient & Diagnosis & Sex/Age & SR & BI & $\begin{array}{c}\text { Previous } \\
\text { treatment }\end{array}$ & $\begin{array}{c}\text { Initial } \\
\text { treatment }\end{array}$ & $\begin{array}{c}\text { Clinical } \\
\text { response }\end{array}$ & $\begin{array}{c}\text { Initial } \\
\text { nitrite + nitrate level }\end{array}$ \\
\hline 1 & BL/RR & M/44 & 60 & 3 & Untreated & Pred 40 & Good & 1658 \\
2 & BT/RR & M/30 & 10 & 0 & Untreated & Pred 60 & Good & 2467 \\
3 & BT/RR & M/57 & 28 & ND & Untreated & Pred 40 & Good & 1956 \\
4 & BT/RR & F/13 & 10 & 0 & MDT-MB & Pred 40 & Poor & 1615 \\
5 & BL/RR & M/44 & ND & 0 & Untreated & Pred 40-60 & Poor & 1114 \\
6 & BL/ENL & F/16 & 76 & 5 & Untreated & Pred 30 & Good & 2055 \\
7 & BL/ENL & M/14 & ND & 3 & Untreated & Pred 30 & Good & 1313 \\
8 & LL/ENL & F/43 & 84 & ND & MDT-MB & Pred 40 & Good & 1529 \\
9 & BL/ENL & F/15 & 8 & 2 & MDT-MB & Pred 40 & Good & 1098 \\
\hline
\end{tabular}

ST; good response, improvement of erythematous skin lesions, no pain or tenderness of skin lesions or peripheral nerves and no or minor loss of peripheral nerve function assessed by VMT/ST compared to the VMT/ST on admission.

\section{ANALYSIS OF NITRITE AND NITRATE}

All urine samples were morning urine samples and were stored at $-20^{\circ} \mathrm{C}$ until analysed. The sum of the nitrate $\left(\mathrm{NO}_{3}{ }^{-}\right)$and nitrite $\left(\mathrm{NO}_{2}{ }^{-}\right)$concentration in urine was determined as described previously. ${ }^{11}$ Urine was diluted in PBS. Nitrate in the samples was reduced to nitrite by incubating the sample with $10 \mu \mathrm{l}$ nitrate reductase from Aspergillus $(10 \mathrm{IU} / \mathrm{ml})$ (Boehringer Mannheim, Freiburg, Germany) and $10 \mu \mathrm{l}$ nicotinamide adenine dinucleotide phosphate (reduced NADPH (Boehringer Mannheim); $1 \mathrm{mM}$ ) for $2 \mathrm{~h}$ at $37^{\circ} \mathrm{C}$. The nitrite level was then determined by Griess reaction. The final reaction volume of $300 \mu \mathrm{l}$ contained $218 \mu \mathrm{l} \mathrm{HCl}(0.45 \mathrm{M}), 26 \mu \mathrm{l}$ sulphanilic acid ( $2 \mathrm{mg} / \mathrm{ml}$ ) (Merck, Darmstadt, Germany), $26 \mu \mathrm{l}$ $\mathrm{N}$-(1-naphthyl) ethylenediamine (1 mg/ml) (Sigma Chemical Co., St Louis, MO, USA) and $30 \mu \mathrm{l}$ of the diluted urine sample. The urine samples were then analysed on an ELISA multiwell reader (Titertec Multiscan Plus) at $542 \mathrm{~nm}$.

\section{STATISTICAL ANALYSIS}

Statistical evaluation was done with the Wilcoxon signed rank test for evaluation on the effect of treatment on the patients. Data are presented as mean \pm SD.

\section{Results}

URINARY LEVELS OF NO METABOLITES IN REACTIONAL LEPROSY PATIENTS

The urinary levels of NO metabolites and the clinical response to prednisolone treatment in leprosy patients admitted because of RR or ENL $(n=9)$ was studied during 6 weeks (Table 1).

The levels of urinary NO metabolites in reactional leprosy patients before high dose 
prednisolone treatment $(1645 \pm 454 \mu \mathrm{M}, n=9, \mathrm{ENL}=4, \mathrm{RR}=5)$ were decreased 2 weeks after treatment $(1075 \pm 414 \mu \mathrm{M}, P<0.05)$ and remained stable $4(895 \pm 385 \mu \mathrm{M}, p<0.02)$ and 6 weeks ( $1048 \pm 452 \mu \mathrm{M}, P<0.02)$ following treatment initiation (Figures 1, 2 and 3). No difference in the levels of NO metabolites in RR $(1762 \pm 497 \mu \mathrm{M}, n=5)$ or ENL $(1499 \pm 410 \mu \mathrm{M}, n=4)$ patients was observed. When the three patients (nos 5, 7 and 9) who did not have increased levels of NO metabolites (defined as less than $1500 \mu \mathrm{M}$ ) initially were excluded, the decrease was even more pronounced with initial levels for untreated reactional patients of $1880 \pm 353 \mu \mathrm{M}(n=6, \mathrm{ENL}=2, \mathrm{RR}=4)$; there was a significant reduction 2 weeks after treatment $(1061 \pm 510 \mu \mathrm{M}, P<0.05)$ which was also stable 4 weeks following treatment initiation $(893 \pm 493 \mu \mathrm{M}, P<0.05)$.

KINETICS OF URINARY NO METABOLITES AND THE CLINICAL RESPONSE IN RR PATIENTS

RR patients had initial urinary NO metabolite levels of $1762 \pm 497 \mu \mathrm{M}(n=5)$, with a reduction 2 weeks after start of prednisolone treatment $(1018 \pm 546 \mu \mathrm{M})$ which remained on similar levels 4 weeks after treatment $(843 \pm 494 \mu \mathrm{M})$ (Figure 2). One patient (no. 5) had an initial low level of urinary nitrite and nitrate $(1114 \mu \mathrm{M})$ despite being clinically in reversal reaction (Figure 2). This patient showed a poor clinical response to steroid treatment and only a slight decrease in NO metabolite levels was observed (Figure 2 and Table 1). One patient (no. 4) showed a poor clinical response to high dose prednisolone treatment and also maintained relatively high levels of NO metabolites, in contrast to the other patients where a marked decrease in urinary NO metabolites coincided with a favourable clinical response (nos 1, 2 and 3) (Figure 2 and Table 1). Patient 3 experienced increasing pain and tenderness in the peripheral nerves (neuritis) between the samples taken at weeks 2 and 3 after treatment initiation which subsided after week 4 . In association with this clinical relapse a peak of NO metabolites was observed 3 weeks after treatment initiation in this patient (Figure 2).

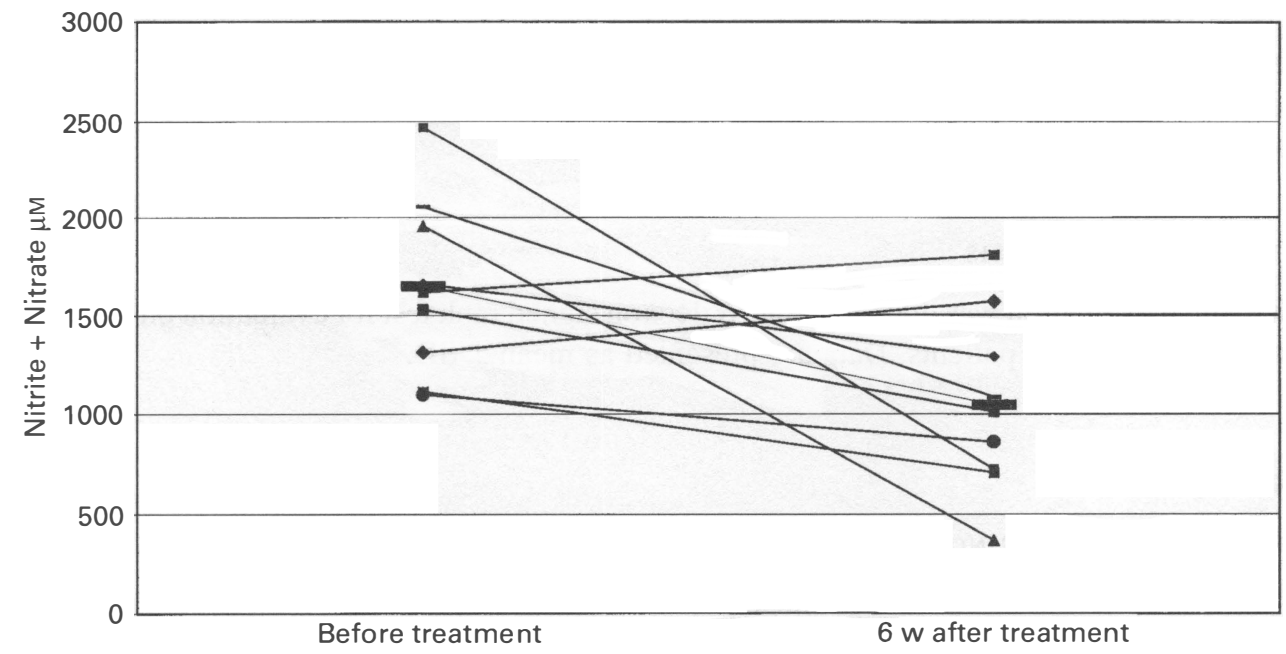

Figure 1. Kinetics of NO metabolites in reactional leprosy patients (ENL + RR, $n=9$ ) before and 6 weeks after initiation of prednisolone treatment. The bold lines indicate the mean levels of nitrite and nitrate before and after treatment. 


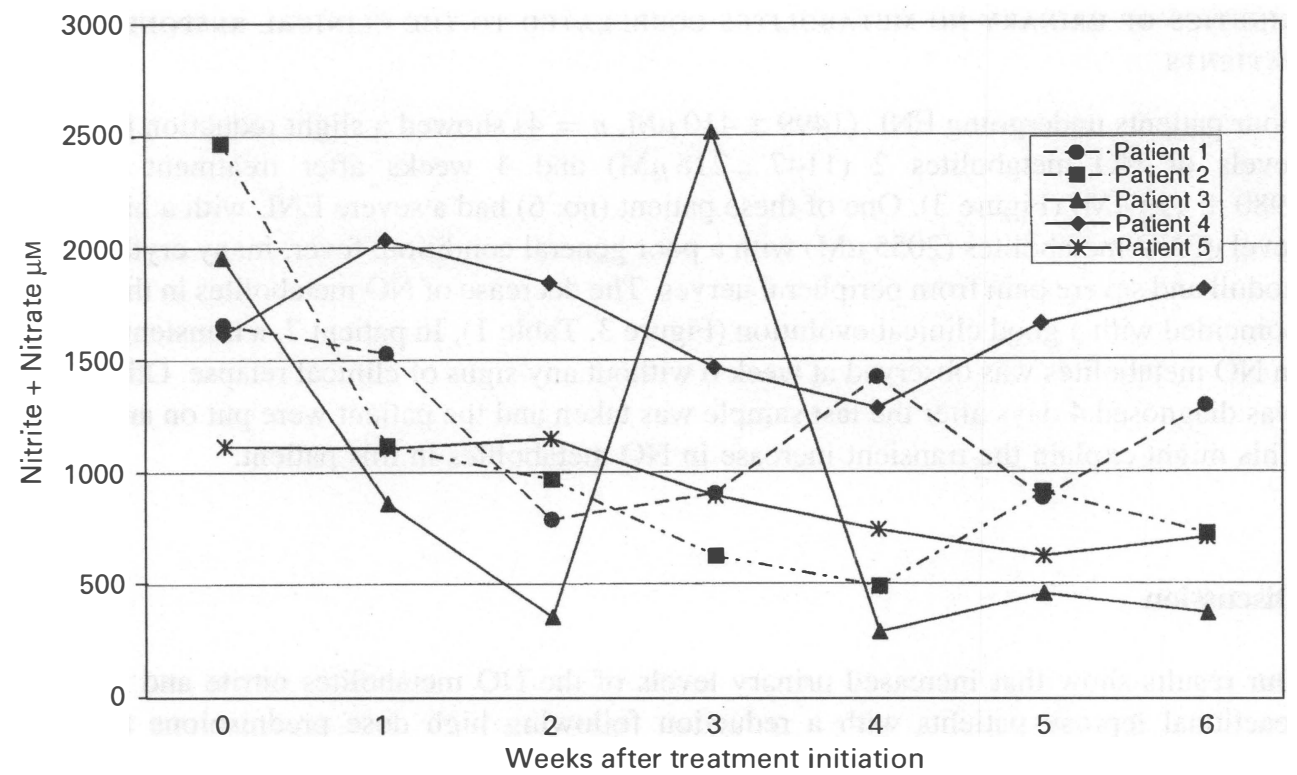

Figure 2. Kinetics of NO metabolites in leprosy patients in reversal reaction (RR, $n=5$ ) before (week 0 ) and up to 6 weeks after initiation of prednisolone treatment. The weekly urinary level of nitrite and nitrate of each patient is indicated.

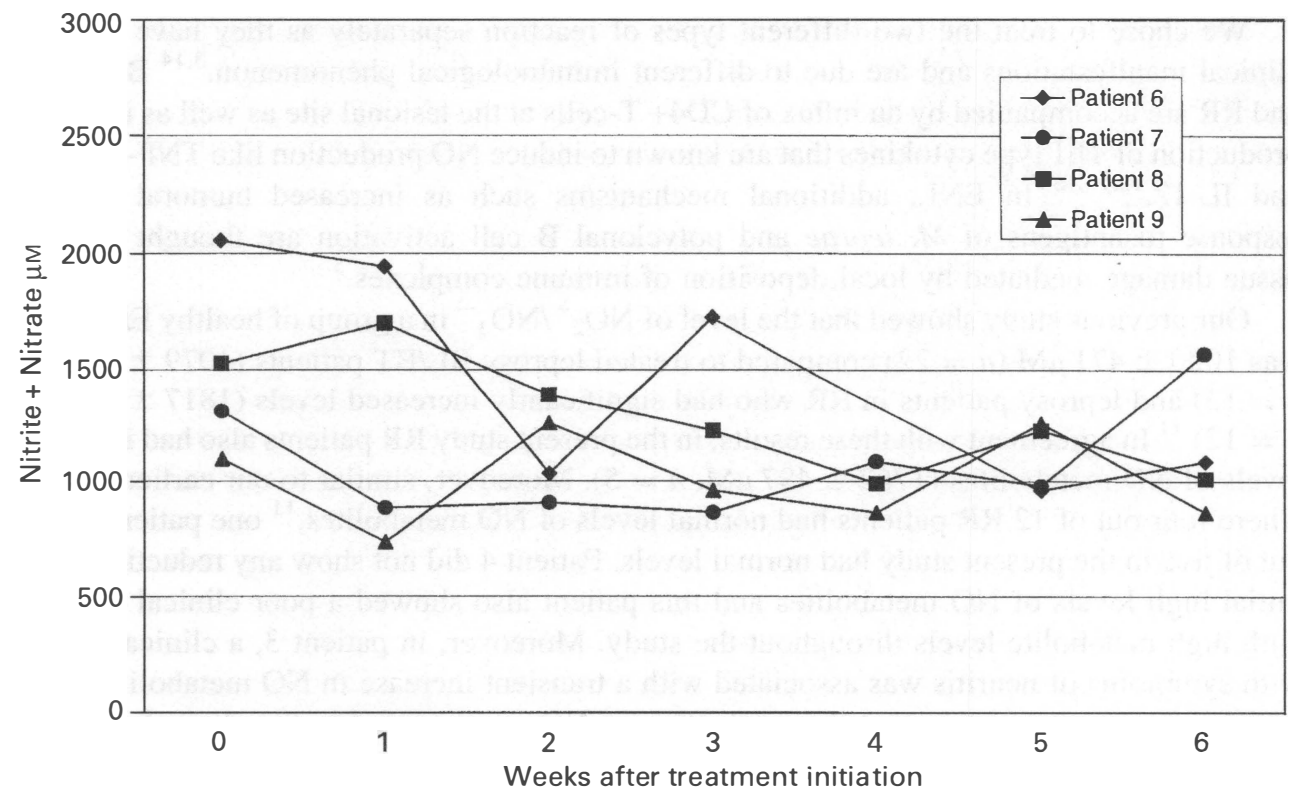

Figure 3. Kinetics of NO metabolites in leprosy patients in erythema nodosum leprosum $(\mathrm{ENL}, n=4)$ before (week 0 ) and up to 6 weeks after initiation of prednisolone treatment. The weekly urinary level of nitrite and nitrate of each patient is indicated. 
KINETICS OF URINARY NO METABOLITES CORRELATED TO THE CLINICAL RESPONSE IN ENL PATIENTS

Four patients undergoing ENL $(1499 \pm 410 \mu \mathrm{M}, n=4)$ showed a slight reduction in urinary levels of $\mathrm{NO}$ metabolites $2(1147 \pm 218 \mu \mathrm{M})$ and 4 weeks after treatment initiation $(980 \pm 113 \mu \mathrm{M})$ (Figure 3). One of these patient (no. 6) had a severe ENL with a high initial level of NO metabolites $(2055 \mu \mathrm{M})$ with a poor general condition, fever, many erythematous noduli and severe pain from peripheral nerves. The decrease of NO metabolites in this patient coincided with a good clinical evolution (Figure 3, Table 1). In patient 7, a transient increase in NO metabolites was observed at week 6 without any signs of clinical relapse. Otitis media was diagnosed 4 days after the last sample was taken and the patient were put on antibiotics. This might explain the transient increase in NO metabolites in this patient.

\section{Discussion}

Our results show that increased urinary levels of the NO metabolites nitrite and nitrate in reactional leprosy patients with a reduction following high dose prednisolone treatment coincides with a favourable clinical response.

It has been shown previously that our method, using an early morning urine sample after an overnight fast, will limit the dietary contribution of nitrite and nitrate and can be used when comparing groups. ${ }^{13}$ Moreover, it is unlikely that dietary factors could explain our results, since the level of urinary NO metabolites in reactional leprosy patients diminished after initiation of prednisolone treatment and remained stable on the same levels as we have shown previously in healthy Ethiopian individuals. ${ }^{11}$

We chose to treat the two different types of reaction separately as they have different clinical manifestations and are due to different immunological phenomenon. ${ }^{3,14}$ Both ENL and $\mathrm{RR}$ are accompanied by an influx of CD4+ T-cells at the lesional site as well as increased production of Th1 type cytokines that are known to induce NO production like TNF- $\alpha$, IFN- $\gamma$ and IL-12. ${ }^{10,15,16}$ In ENL, additional mechanisms such as increased humoral immune response to antigens of $M$. leprae and polyclonal B cell activation are thought to cause tissue damage mediated by local deposition of immune complexes. ${ }^{5}$

Our previous study showed that the level of $\mathrm{NO}_{2}{ }^{-} / \mathrm{NO}_{3}{ }^{-}$in a group of healthy Ethiopians was $1020 \pm 471 \mu \mathrm{M}(n=22)$ compared to treated leprosy BL/BT patients $(1079 \pm 446 \mu \mathrm{M}$, $n=12)$ and leprosy patients in RR who had significantly increased levels $(1817 \pm 492 \mu \mathrm{M}$, $n=12) .{ }^{11}$ In agreement with these results, in the present study RR patients also had increased levels of NO metabolites (1762 $\pm 497 \mu \mathrm{M}, n=5)$. Moreover, similar to our earlier findings where four out of 12 RR patients had normal levels of NO metabolites, ${ }^{11}$ one patient (no. 5) out of five in the present study had normal levels. Patient 4 did not show any reduction of the initial high levels of NO metabolites and this patient also showed a poor clinical response with high metabolite levels throughout the study. Moreover, in patient 3, a clinical relapse with symptoms of neuritis was associated with a transient increase in NO metabolite levels, supporting our observation that the production of NO is associated to the clinical response. One possible explanation for our results might be that prednisolone treatment prevents NO mediated tissue damage, as RR cases left untreated are often severely disabled because of nerve damage. However, other NO independent pathways of tissue damage also seems to be present as in some patients suffering from RR, no increase in urinary NO metabolite levels is 
observed. Other explanations could be that there is a small local production of NO in the skin which can not be detected by urinary NO metabolites or lack of the substrate for NO production, L-arginine, because of malnutrition.

In this study, we also describe a role for NO in ENL patients as these patients had increased levels of NO metabolites that were reduced after prednisolone treatment accompanied by a favourable clinical response. Further studies with higher numbers of patients are necessary to confirm the role for NO in ENL, but it has been shown that tissue injury resulting from deposition of immune complexes is L-arginine dependent, ${ }^{17}$ indicating that $\mathrm{NO}$ might be an important mediator in immune complex mediated diseases such as ENL.

It has been shown that glucocorticoids inhibit iNOS and NO production directly through inhibition of the translocation of nuclear factor kappa beta as well as indirectly by suppressing the production of cytokines such as TNF- $\alpha .{ }^{18}$ The main mechanism by which prednisolone exerts its effects in reactional leprosy patients remains to be established as the drug affects many inflammatory mechanisms such as inhibition of the cyclo-oxygenase. ${ }^{19}$

This study indicates that an iNOS inhibitor drug might be of benefit for the treatment of reactions in leprosy and that the relatively fast and cheap method of determining the NO metabolites nitrite and nitrate in morning urine samples might be useful in monitoring the response to treatment in leprosy reactions. Specific iNOS inhibitors with fewer side effects than high dose steroids need to be searched for in the treatment of reactions in leprosy patients.

\section{Acknowledgements}

This work was supported by King Gustav Vth 80 year Foundation.

\section{References}

${ }^{1}$ Ridley DS, Jopling WH. Classification of leprosy according to immunity. A five group system. Int J Lepr, 1966; 34: 255-273.

2 Modlin RL. TH1-Th2 paradigm: insights from leprosy. J Invest Dermatol, 1994; 102:828-832.

3 Jopling WH. Classification of reactions in leprosy. Lepr Rev, 1970; 41:62-63.

4 Khanolkar-Young S, Rayment N, Brickell PM et al. Tumor necrosis factor alpha (TNF- $\alpha$ ) synthesis is associated with the skin and peripheral nerve pathology of leprosy reversal reactions. Clin Exp Immunol, 1995; 99:196-202

5 Wemambu SNC, Turk JL, Waters MFR, Rees RJW. Erythema nodosum leprosum: a clinical manifestation of the Arthus phenomenon. Lancet, 1969; ii, 933-935.

6 Modlin RL, Bakke AC, Vaccaro SA et al. Tissue and blood T-lymphocyte subpopulations in erythema nodosum leprosum. Arch Dermatol, 1985; 121: 216-219.

7 Naafs B. Treatment of reactions and nerve damage. Int J Lepr, 1996; 64: S21.

8 Änggård E. Nitric oxide: mediator, murderer and medicine. Lancet, 1994; 343: 1199-1206.

9 De Groote MA, Fang FC. NO inhibitions: antimicrobial properties of nitric oxide. Clin Invest Dis, 1995; 21: S162-165.

10 MacMicking J, Xie Qiao-Wen, Nathan C. Nitric oxide and macrophage function. Annu Rev Immunol, 1997; 15: 323-350.

11 Schön T, Gebre N, Sundqvist T et al. Increased levels of nitric oxide metabolites in urine from leprosy patients in reversal reaction. Lepr Rev, 1999; 70: 52-55.

12 Khanolkar-Young S, Snowdown D, Lockwood DNJ. Immunocytochemical localisation of inducible nitric oxide synthase and transforming growth factor- $\beta$ in leprosy lesions. Clin Exp Immunol, 1998; 113:438-442.

13 Rhodes P, Leone AM, Francis PL, Struthers AD, Moncada S, Rhodes PM. The L-arginine:nitric oxide pathway is the major source of plasma nitrite in fasted humans. Biochem Biophys Res Commun, 1994; 209: 590-596.

14 Moubasher AEA, Kamel NA, Zedan H, Abdel Raheem AE-D. Cytokines in leprosy II. Effect of treatment on serum cytokines in leprosy. Int J Dermatol, 1998; 37: 741-746. 
15 Modlin RL, Gebhard JF, Taylor CR, Rea TH. In situ characterization of T lymphocyte subsets in the reactional states of leprosy. Clin Exp Immunol, 1983; 53: 17.

16 Sreenivasan P, Mirsa RS, Wilfred D, Nath I. Lepromatous leprosy patients show T helper 1-like cytokine profile with differential expression of interleukine-10 during type 1 and 2 reactions. Immunology, 1998; 95: 529-536.

17 Mulligan MS et al. Immune complex mediated damage is L-arginine dependent. Proc Natl Acad Sci, 1991; 88: 6338-6342.

${ }^{18}$ Szabo C. Regulation of the expression of the inducible isoform of nitric oxide synthase by glucocorticoids. Ann $N$ Y Acad Sci, 1998; 851: 336-341.

19 Rang HP, Dale MM, Ritter JM. Pharmacology 3rd Edition. Churchill Livingstone, USA, 1995, p. 439. 